\title{
LA CLÁUSULA QUE HABILITA A LA EMPRESA DE MEDICINA PREPAGA A INCREMENTAR EL VALOR DE LA CUOTA EN BASE A LA EDAD DEL AFILIADO: SU ENCUADRE EN LA ENUMERACIÓN DEL ART. 37 DE LA LEY 24.240 DE ARGENTINA
}

Autora: Florencia Vazzano

Filiación institucional: Facultad de Derecho de la Universidad Nacional del Centro de la Provincia de Buenos Aires

Integrante del Instituto de Estudios Jurídicos y Sociales (IEJUS) de esa Facultad. Correo electrónico: florencia.vazzano@azul.der.unicen.edu.ar

\section{Resumen:}

En el presente trabajo nos centraremos en la cláusula del contrato de medicina prepaga por la cual la empresa prestadora del servicio dispone unilateralmente su facultad de aumentar la cuota del afiliado en razón de su mayor edad. Su análisis se realizará desde la enumeración de cláusulas abusivas del art. 37 inc. a y b de la ley 24.240 de Defensa del Consumidor y los efectos previstos por esta ley, y la ley 26.682 que establece el marco regulatorio de las empresas de medicina prepaga. Asimismo, seleccionamos jurisprudencia argentina que ha declarado la nulidad de tal clausula por considerarla abusiva y lesiva del derecho a la salud del afiliado a empresa, derecho que tiene jerarquía constitucional.

Palabras claves: Medicina prepaga-incremento de la cuota- edad del afiliado-_clausula abusiva-_nulidad.

\begin{abstract}
In this paper we focus on the contract clause prepaid medical why the utility company unilaterally has the power to increase the share of affiliate because of their older age. Their analysis will be from the list of unfair terms of art. $37 \mathrm{inc}$. b of the Law 24,240 on Consumer and effects provided by this law, and the law 26,682 which establishes the regulatory framework for prepaid medicine companies.Also, select Argentina jurisprudence has declared the nullity of such clause considered abusive and harmful for the right to health of the affiliated company, which has constitutional right.
\end{abstract}

Keywords: HMOs- increasing the share__Adult Affiliate-_abusive clause- nullity 


\section{El contrato de Medicina Prepaga}

En primer lugar, partiremos del concepto de contrato de medicina prepaga y sus caracteres.

Siguiendo la definición de Lorenzetti, es el contrato mediante el cual una de las partes se obliga a prestar servicios médicos a los pacientes, por sí o por terceros, sujeta a la condición suspensiva de que se dé una determinada enfermedad en el titular o beneficiario, contra el pago de un precio anticipado y periódico. ${ }^{1}$

Es un contrato de adhesión, es decir, de aquellos cuyas cláusulas son preformuladas por una sola de las partes (empresa de medicina prepaga) y aceptadas o rechazadas por el adherente (paciente), sin poder modificarlas. El nuevo Código Civil y Comercial de la Nación brinda una definición de contrato por adhesión en su art. 984 como "aquel mediante el cual uno de los contratantes adhiere a cláusulas generales predispuestas unilateralmente, por la otra parte o por un tercero, sin que el adherente haya participado en su redacción”.

Es un contrato de consumo conforme el ámbito de aplicación subjetivo (art. $1^{\circ}$ y $2^{\circ}$ ) y objetivo (art. $3^{\circ}$ ) de la ley 24.240 de Defensa del Consumidor. Asimismo, el nuevo Código Civil y Comercial de la Nación recepta también el contrato de consumo en el Título III del Libro sobre Derechos Personales. ${ }^{2}$

Es un contrato aleatorio, de modo que el usuario no sabe si va a requerir los servicios médicos o no, lo cual depende de un acontecimiento futuro e incierto (la enfermedad). Es un contrato de larga duración, es decir que se celebra para perdurar en el tiempo.

${ }^{1}$ LORENZETTI, Ricardo L., “Consumidores”, Rubinzal Culzoni, Santa Fe, 2003, pág. 330.

${ }^{2}$ El art. 1093 del nuevo Código Civil y Comercial de la Nación dispone: "Contrato de consumo. Contrato de consumo es el celebrado entre un consumidor o usuario final con una persona humana o jurídica que actúe profesional u ocasionalmente o con una empresa productora de bienes o prestadora de servicios, pública o privada, que tenga por objeto la adquisición, uso o goce de los bienes o servicios por parte de los consumidores o usuarios, para su uso privado, familiar o social". 
El predisponente de este contrato es una empresa que funciona como intermediaria entre los profesionales de la salud y el usuario, esto difiere, por tanto, del modelo más tradicional en el que el paciente recurre al médico y le paga sus honorarios. Esta intermediación genera una actividad que se basa en la captación del ahorro en forma anticipada de un grupo de personas, contra la dación futura y en condiciones predeterminadas de atención médica.

\section{Las cláusulas abusivas en la Ley de Defensa del Consumidor argentina}

Conforme el art. 37 del Decreto 1798/94, reglamentario de la ley 24.240, "se consideran términos o cláusulas abusivas a las que afectan inequitativamente al consumidor o usuario en el cotejo entre los derechos y obligaciones de ambas partes".

En general, pueden definirse como "aquellas que se imponen unilateralmente por una de las partes de la relación negocial, perjudicando a la otra parte, o determinando una posición de desequilibrio entre los derechos y las obligaciones de los contratantes, en perjuicio, por lo común, de los consumidores y usuarios..." 3

El nuevo Código Civil y Comercial de la Nación brinda un concepto de cláusula abusiva en su art. 1119, el cual dispone lo siguiente: "Regla general. Sin perjuicio de lo dispuesto en las leyes especiales, es abusiva la cláusula que, habiendo sido o no negociada individualmente, tiene por objeto o por efecto provocar un desequilibrio significativo entre los derechos y las obligaciones de las partes, en perjuicio del consumidor.

La ley 24.240 contiene en su art. 37 distintos supuestos que permiten establecer los parámetros para determinar cuándo una cláusula tiene carácter de abusiva según nuestro ordenamiento jurídico. Dicha norma prevé dos estándares generales: 1) cláusulas que desnaturalizan las obligaciones en el inc. a primera parte y, 2) cláusulas que importan renuncia o restricción de los derechos del consumidor o amplían los derechos de la otra parte, en el inc. b. Luego contiene dos cláusulas particulares: 3) las que limitan la responsabilidad por daños, en el inc. a segunda parte y, 4) las cláusulas que contengan

\footnotetext{
${ }^{3}$ FARINA, Juan M., "Defensa del Consumidor y del Usuario, comentario exegético de la ley 24.240 y del dec. Reglamentario 1798/94”, Astrea, Bs. As., 1995, pág. 284.
} 
cualquier precepto que imponga la inversión de la carga de la prueba en perjuicio del consumidor, en el inc. c.

Como señala Stiglitz, "la prohibición de una cláusula abusiva constituye un limite a la autonomía de la voluntad impuesto por la norma jurídica que así la califica (...) En otras palabras, la norma que prohíbe que en los contratos de consumo, determinadas clausulas integren el contenido del contrato, tiene la eficacia de impedir, imperativamente, que se consagren derechos excesivos a favor del empresario $u$ obligaciones vejatorias contra el consumidor". 4

Veamos la enumeración del art. 37 de la ley 24.240:

a) Cláusulas que desnaturalizan las obligaciones de las partes: Siguiendo a Lorenzetti, una cláusula de este tipo implica que existe algo "natural" en el contrato que es modificado. Este término debe entenderse en el sentido de normalidad del contrato, que va a estar determinada por el modelo que el legislador consideró razonable, y que suministra a las partes para que éstas lo tomen en cuenta. De este modo si una cláusula se aparta del sistema de razonabilidad, injustificadamente, resulta irrazonable, y por tanto desnaturaliza las obligaciones de una de las partes del negocio. ${ }^{5}$ (Lorenzetti, 2003, pág. 246-247).

b) Cláusulas que importan renuncia o restricción de los derechos del consumidor o amplían los derechos de la otra parte: Se trata de un supuesto que se encuentra comprendido en el inc. a del art. 37, es decir, un caso de desnaturalización de obligaciones.

La ley no establece un catálogo de derechos del consumidor; para determinarlos hay que recurrir a la propia ley 24.240 y al resto de la normativa que la integra, conforme su art. 3.

\footnotetext{
4 STIGLITZ, Gabriel, "Cláusulas abusivas. Inconstitucionalidad de normas restrictivas contra los consumidores", disponible

http://www.academiadederecho.org/upload/biblio/contenidos/Jurisprudencia_Rosarina_Clausulas_Abusi vasStiglitz.pdf. Consulta realizada el 6/11/2014.

${ }^{5}$ LORENZETTI, Ricardo, L., “Consumidores”, Rubinzal-Culzoni, Santa Fe, pàg. 246-247.
} 
Cabe aclarar, que no se trata de que el usuario no pueda renunciar a nada, sino que no puede imponérsele renuncias que le impidan alcanzar la finalidad práctica del contrato o que desequilibre la relación. ${ }^{6}$ (Lorenzetti, 2003, pág. 248-249).

c) Cláusulas que limitan la responsabilidad por daños: "Esta previsión considera abusivas las cláusulas que limiten la responsabilidad por daños que le incumbe al proveedor, tanto por el incumplimiento de la prestación principal (art. 10 bis) como de la obligación de seguridad (art. 5), y también los supuestos de daños ocasionados por vicio o riesgo de la cosa o del servicio”. “...el deudor de una prestación se exonera de reparar los daños que una ejecución imperfecta o una inejecución pudiera causar a la persona, a los bienes o a los intereses patrimoniales de su cocontratante"

d) Cláusulas que contengan cualquier precepto que imponga la inversión de la carga de la prueba en perjuicio del consumidor: "El art. 37, LDC, prevé también la abusivisad de las cláusulas que contemplen una inversión de la carga de la prueba en perjuicio del consumidor, en cualquier supuesto en que esto se produzca”. Se trata, en definitiva, del caso en que el proveedor se exime -mediante disposición expresade producir la prueba que le incumbe, o deja de lado las morigeraciones previstas por la normativa vigente a favor del consumidor.

\subsection{La cláusula que habilita a la empresa a incrementar el monto de la cuota en} razón de la edad del afiliado: Su encuadre en la enumeración del art.37 de la ley 24.240

\footnotetext{
${ }^{6}$ LORENZETTI, Ricardo, L., op.cit., pàg. 248-249.

7 SAENZ Luis R. J., "De los términos abusivos y las cláusulas ineficaces”, en Ley de Defensa del consumidor, comentada y anotada, T. I, Parte General, dirigida por Picasso y Vazquez Ferreyra, La Ley, Avellaneda, Pcia. de Bs. As., 2009, pág. 450.

${ }^{8}$ SAENZ, Luis R. J., "De los términos abusivos y las cláusulas ineficaces”, en Ley de Defensa del consumidor, comentada y anotada, T. I, Parte General, dirigida por Picasso y Vazquez Ferreyra, La Ley, Avellaneda, Pcia. de Bs. As., 2009, pág. 454.
} 
Habiendo repasado la enumeración de cláusulas abusivas del art. 37 de la ley 24.240, nos centraremos en la cláusula que habilita a la empresa de medicina prepaga a incrementar el monto de la cuota, en base a la edad avanzada del adherente, generalmente de 65 años o más.

Muchas veces no está especificado en el contrato que tal facultad de modificación unilateral puede obedecer a dicha causa.

Surge así, el interrogante sobre si es posible que la entidad pueda o no incorporar al contrato cláusulas de este tipo. Estas empresas suelen alegar que a partir de cierta edad, los requerimientos asistenciales de sus afiliados se incrementan, lo cual exige mayores erogaciones. Ahora bien, la cuestión que se plantea es si dichas entidades pueden trasladar los costos al usuario, o se trata de un riesgo que debe ser previsto y asumido por ellas.

Pues bien, la abusividad de esta cláusula resulta incuestionable. La misma encuadra en el supuesto contemplado en el inc. b del art. 37 LDC, es decir, se trata de un supuesto de renuncia de los derechos del consumidor o ampliación de los derechos de la otra parte, que no es más que un caso de desnaturalización de obligaciones del inc. a, que la norma prevé como estándares generales.

Se trata de una cláusula que por ser abusiva genera una doble vulnerabilidad en el usuario del servicio médico: por un lado, la derivada de la condición de usuario, es decir, por tratarse de la parte débil de este contrato de adhesión, y por otro lado, por tratarse de personas mayores de edad, incluso ancianas, las cuales necesitan protección específica del ordenamiento jurídico.

Una cláusula que además afecta derechos fundamentales del afiliado, tales como el derecho a la salud ${ }^{9}$ consagrado en instrumentos internacionales sobre derechos humanos de jerarquía constitucional a partir de la reforma de 1994, y en el art. 42 de nuestra ley fundamental que otorga protección específica a los consumidores y usuarios de bienes y servicios.

\footnotetext{
${ }^{9}$ Conforme la definición del Preámbulo de la Constitución de la Organización Mundial de la Salud adoptada por la Conferencia Sanitaria Internacional, celebrada en Nueva York del 19 de junio al 22 de julio de 1946, firmada el 22 de julio de 1946 por los representantes de 61 Estados, y en vigor desde el 7 de abril de 1948, "La salud es un estado de completo bienestar físico, mental y social, y no solamente la $\begin{array}{lllll}\text { ausencia de afecciones } & \text { o } & \text { enfermedades. } & \text { Disponible } & \text { en }\end{array}$ http://www.who.int/governance/eb/who_constitution_sp.pdf. Extraído el día 01/04/2015.
} 
"Con el art. 42 de la Constitución Nacional se constitucionalizó el derecho del consumidor, instituyéndolo como un derecho de tercera generación..."

"La salud constituye un bien jurídico protegido de los consumidores, quienes muchas veces son víctimas de los abusos y de un mercado de salud que funciona asimétricamente al responder en muchos casos a otros intereses que no son los de los usuarios de medicina prepaga, ofreciendo una mayor desprotección a sus derechos (ej. frente a la aplicación de aumento a la cuota a medida que la edad del usuario o consumidor aumenta)". ${ }^{11}$

Resulta conculcado además el derecho a la igualdad, en tanto se pretende un trato diferente hacia las personas mayores de edad en base a un criterio- la edad- que no resulta un medio razonable para aumentar el monto de la cuota (finalidad).

Por último, se ven afectados los intereses económicos, que encuentran protección específica en el art. 42 de la Constitución Nacional, ya que el aumento de la cuota en edades como las previstas en las cláusulas en tratamiento- 70 años generalmentemomento en que el poder adquisitivo disminuye, puede generar que el pago de la misma se torne oneroso, cuando los aumentos dispuestos consisten en porcentajes elevados.

Como señala Berbere Delgado estamos ante un negocio jurídico que tiene intensificado el rol protectorio del usuario en función de la actividad sensible que lleva adelante el empresario. Se trata de una obligación de medios custodiada, que no puede limitarse a la esfera de protección del consumidor, habida cuenta de que los derechos que hacen a su personalidad vienen de un estadio superior naturalmente frente a todo tipo de relación contractual que pueda establecer el consumidor con el empresario ${ }^{12}$.

\footnotetext{
${ }^{10}$ ARIAS CÁU, Esteban J., "La defensa del consumidor: pasado, presente y futuro a la luz del Proyecto de Còdigo Civil 2012", en http://www.acaderc.org.ar/doctrina/la-defensa-del-consumidor-pasadopresente-y-futuro-a-la-luz-del-proyecto-de-codigo-civil-de-2012. Consulta realizada el 11/12/2014.

${ }^{11}$ MAC DONALD, Andrea F., "La medicina prepaga y el aumento de las cuotas a los consumidores", en Revista Microiuris, MJ-DOC-5087-AR | MJD5087, 2010.
}

12 BERBERE DELGADO, Jorge C., "El usuario de Empresas de Medicina Prepaga. Su naturaleza jurídica, en La Ley, Suplem. Règimen jurídico de la Medicina Prepaga, mayo 2011, p. 22. 
Siguiendo a Sandra Frustagli, "el contrato de medicina prepaga, en cuanto consiste en una operación a través de la cual el afiliado pretende asegurar la atención de su salud o la de su grupo familiar, se involucran derechos de jerarquía constitucional como el derecho a la salud y a la vida, según ya se dijo. El fenómeno descripto convierte a este negocio en un campo donde los intereses patrimoniales tensionan con derechos primarios, dejando al descubierto -en el plano axiológico- un conflicto de valores entre utilidad-humanidad"13

Por los fundamentos expuestos, es de aplicación el inc. b del art. 37 de la LDC, en tanto, la cláusula en tratamiento, importa para el usuario una renuncia a su derecho a la vida, a la salud y a la protección de sus intereses económicos; o una ampliación de los derechos de la empresa, en tanto le permite la modificación unilateral de un elemento esencial del contrato, como es el precio de los servicios, de acuerdo a sus conveniencias económicas y en base a un criterio no razonable: la edad del afiliado.

"La renuncia que prevé el art. 37 inc. b, opera cuando se han impuesto obstáculos en el camino al acceso del bien o servicio contratado, como sucede en este caso, ya que el aumento del importe que el paciente debe abonar para quedar indemne frente a enfermedades que con más frecuencia se presentan en edades avanzadas, puede impedir que obtenga los servicios médicos contratados. Esto porque puede verse obligado -ante la onerosidad que le provoca seguir cumpliendo con su prestación- a retirarse del sistema, e incluso que cuando quiera ingresar a otras empresas de Medicina Prepaga u obras sociales sea rechazado, dadas las condiciones de ingreso que se suelen imponer (carencias, preexistencias, incluso por su edad avanzada, etc.).

La norma en cuestión "tiene por finalidad evitar que se le puedan imponer renuncias que impida su acceso al bien o servicio, o que afecten aspectos no patrimoniales (integridad física, salud, honor) o que se desequilibre la justicia conmutativa del contrato". ${ }^{14}$

13 FRUSTAGLI, Sandra A., "El contrato como marco de tensión entre utilidad y derechos de la personalidad”, en RCyS, julio 2010, p. 24 y ss.

14 Sáenz Luis R. J., "De los términos abusivos y las cláusulas ineficaces", en Ley de Defensa del consumidor, comentada y anotada, T. I, Parte General, dirigida por Picasso y Vazquez Ferreyra, La Ley, Avellaneda, Pcia. de Bs. As., 2009, pág. 452. 
En suma, se observa un abuso de la posición dominante que ejerce el predisponente, susceptible de alterar el equilibrio que debe existir- dado que tal cláusula lo favorece excesivamente y perjudica inequitativamente al usuario. Esto porque si bien es cierto que las personas al llegar a determinada edad requieren con más frecuencia de los servicios que la empresa brinda, lo cual implica mayores erogaciones, éste es un riesgo que debe ser asumido por ésta y se trata de una de las previsiones que debe ser evaluada anticipadamente al momento del ingreso del adherente.

Al decir de Lorenzetti, "la empresa percibe una masa de dinero aportada por un grupo, y sólo una parte de ellos gasta, de modo que si se mantiene este equilibrio, puede pagarle a los enfermos, soportar sus gastos, y obtener una ganancia. El cálculo probabilístico es el que posibilita este funcionamiento. El riesgo de la empresa reside en hacer bien o mal el cálculo, en administrar mejor o peor, en el modo de selección de su cartera, en la diversificación de riesgos. La empresa puede disminuir esos riesgos o aumentarlos, según sea más o menos seria, más o menos eficiente, lo que no puede hacer es trasladarlos". 15

Como señala Weingarten, "las medicinas prepagas establecen sus prestaciones como cualquier empresa en la relación costo-beneficio e incluso como cualquier empresa como lo pregonaban Ricardo y Smith- tratarán de "maximizar sus ganancias".

No existen en economía milagros, la maximización de la ganancia se realiza por "supresión de costos" o en mercados cautivos "con aumentos de precio" y ello se traduce -solo una parte- en el ámbito del derecho en prácticas abusivas y cláusulas abusivas (se trata de la derivación de riesgos económicos al usuario)". ${ }^{16}$

Pero no podemos de dejar de remarcar el criterio de nuestra jurisprudencia en cuanto a la naturaleza de la función que cumplen-o que al menos deben cumplir- las empresas de medicina prepaga: "si bien presentan rasgos mercantiles en razón de que tienden a

\footnotetext{
${ }^{15}$ LORENZETTI, Ricardo L., “Tratado de los Contratos”, T. I, Rubinzal-Culzoni, Santa Fe, 2004, pág. 70.

${ }^{16}$ WEINGARTEN, Celia, “Cláusulas abusivas. Análisis económico y jurisprudencial”, en Revista Microuris, MJ-DOC-5409-AR | MJD5409, 2011.
} 
proteger las garantías a la vida, salud, seguridad e integridad de las personas, adquieren un cúmulo de compromisos que exceden o trascienden el plano negocial". ${ }^{17}$

La Resolución n $n^{\circ}$ 53/2003, de la Secretaría de la Competencia, la Desregulación y la Defensa del Consumidor: La autoridad de aplicación de la ley 24.240, mediante el dictado de distintas Resoluciones, ha establecido un listado de cláusulas que se consideran abusivas. La Resolución $n^{\circ}$ 53/2003, de la Secretaría de la Competencia, la Desregulación y la Defensa del Consumidor (modificada por Disposición 3/2003 de la Subsecretaría de la Defensa de la Competencia y Defensa del Consumidor, y por Resolución 26/2003 y 9/2004 de la Secretaría de Coordinación Técnica) contiene en su Anexo una enumeración de carácter enunciativa de cláusulas de este tipo, entre las que se encuentra, aquella que otorga al proveedor la facultad de modificar unilateralmente el contrato, excepto en aquellos casos que la autoridad de aplicación determine conforme pautas y criterios objetivos.

La Resolución 9/2004 de la Secretaría de Coordinación Técnica complementa y modifica la mencionada Resolución, estableciendo que son consideradas abusivas las cláusulas que otorgan al proveedor la facultad de modificar unilateralmente el contrato, excepto en relación con los que se celebren por tiempo indeterminado, y que además reúnan ciertos recaudos: a) que los eventuales cambios se hallen expresamente previstos en el contrato. Dispone que tales cambios pueden obedecer a causas fundadas en incorporaciones de servicios, tecnologías o prestaciones; b) que tales cambios revistan carácter de general y no se refieran a un consumidor en particular; c) que los mismos no alteren el objeto del contrato o importen un desmedro en la calidad de los servicios comprometidos al momento de la contratación; d) que se encuentre prevista la notificación del cambio al usuario, con antelación no inferior a sesenta días de la entrada en vigor de la modificación, con la posibilidad para el consumidor de rescindir el negocio si no la acepta.

La facultad de modificación unilateral de la empresa en razón de la edad del afiliado no obedece a pautas o criterios objetivos y, por tanto, no es posible enmarcarla como excepción que habilita la aprobación de la autoridad de aplicación, conforme lo expresa

\footnotetext{
${ }^{17}$ MORELLO, María Silvia-SCHERMAN, IDA A., "Los contratos de Medicina Prepaga y el derecho a la salud de los niños y adolescentes bajo la mirada de los instrumentos de derechos humanos", Revista de Derecho de Familia, pàg. 42-99, citando a CSJN, en Hospital Britànico (Fallos 324:754 del 13/3/2001) y Etcheverry (Fallos 324:677 del 13/3/2001).
} 
la Resolución no 53 mencionada. Es decir, esta atribución que se adjudica la entidad obedece a un criterio puramente subjetivo porque atiende a una cualidad de la persona, como es la edad. Distinto es si se estipula la posibilidad de modificación unilateral del contrato por el predisponente en base a causas objetivas, externas, preestablecidas y conocidas por el usuario, previendo eventuales cambios, como la ampliación de las prestaciones a cargo de la empresa o la incorporación o sustitución de tecnologías más costosas, o incluso, cambios en la economía del país que desencadenan la devaluación de la moneda y que tornan más onerosa las obligaciones del ente. En estos supuestos, la entidad está habilitada para aumentar el valor de la cuota, pero extender esta facultad a los casos en que el afiliado, en razón de su edad, requiere más menudo de sus servicios, importa una ampliación de los derechos del sujeto predisponente, en los términos del inc. $\mathrm{b}$ del art. 37 LDC.

Autores, como Lorenzetti, han señalado que las partes pueden establecer, en la celebración del contrato, las causas objetivas por las cuales puede ser modificado, con derecho de rescisión por parte del consumidor. Es posible prever mecanismos contractuales de modificación del contenido obligacional atendiendo a que es previsible que se produzcan cambios, siempre que se resguarden debidamente los derechos de las partes mediante mecanismos objetivos que inhiban las imposiciones unilaterales o potestativas. $^{18}$

Por otro lado, no se cumplen los requisitos que la Res. 9/2004 mencionada establece para los supuestos de excepción, cuando no se prevé en el mismo contrato la posibilidad de aumento del valor de la cuota en razón de la edad del afiliado, vulnerando gravemente el derecho del usuario a una información cierta, clara y detallada. Esto implica también ausencia del recaudo que exige que esté previsto la notificación del cambio al usuario para darle la oportunidad de rescindir el contrato. Se afecta, además, la calidad del servicio contratado si se ve obligado a cambiar a una categoría de asociado donde la asistencia médica no contiene la misma tecnología o calidad profesional.

- El supuesto del inc. b del art. 37 queda comprendido en el inc. a de la misma disposición dado que se trata, en definitiva, de un caso de desnaturalización de obligaciones.

${ }^{18}$ LORENZETTI, Ricardo L., “Consumidores”, Rubinzal Culzoni, Santa Fe, 2003, pàg. 260. 
Siguiendo el pensamiento de Lorenzetti, al cual la doctrina en general se adhiere, una cláusula que desnaturaliza obligaciones es aquella que produce la derogación injustificada del derecho supletorio, que es el modelo que el legislador ha considerado razonable. Por ello, la cláusula se vuelve abusiva cuando se aparta de ese modelo natural, normal. ${ }^{19}$

Una estipulación contractual que permite al predisponente incrementar el monto de la cuota del usuario en base a su edad, altera injustificadamente la distribución de riesgos del contrato. Es decir, el envejecimiento natural de los pacientes y las mayores demandas de los servicios y mayores erogaciones que ello conlleva, configuran contingencias que son propias de la actividad que desarrolla la empresa y que están comprendidas dentro de su obligación de prestar el servicio. Se trata de un riesgo que debe ser asumido por ésta y evaluado anticipadamente al momento del ingreso del adherente. Por ello, el traslado de este riesgo al usuario, en base a su edad, carece de justificación y desnaturaliza la obligación de la empresa.

La cláusula tratada afecta lo que Lorenzetti ha denominado "correspectividad de las prestaciones", referida a la reciprocidad que debe existir entre las obligaciones de las partes, durante todo el cumplimiento de un contrato de larga duración. La norma del art. 37 de LDC al determinar cuándo una cláusula es abusiva, presupone que debe existir esa reciprocidad y busca evitar que ella se vea afectada. Lorenzetti indica que "mientras en los contratos de cumplimiento instantáneo o diferido la correspectividad de las prestaciones se mide en un lapso de tiempo relativamente breve, en los contratos de larga duración con elementos de previsión, la correspectividad se mide en largos períodos. Pago ahora para recibir prestaciones dentro de veinte o treinta años. Se trata de una correspectividad de larga duración. Este concepto sirve para solucionar casos que se han dado con frecuencia, en razón de la diferente utilidad marginal que plantean estos negocios. El consumidor paga más al principio y gana al final, mientras que la empresa, inversamente, gana más al principio y gasta más al final. La empresa se verá tentada a incluir una cláusula de rescisión unilateral sin causa o con causa a una determinada edad del cliente". ${ }^{20}$

\footnotetext{
${ }^{19}$ LORENZETTI, Ricardo L., op. cit., pàg. 246-247.

${ }^{20}$ LORENZETTI, Ricardo L., “Tratado de los contratos”, T. III, Rubinzal-Culzoni, Santa Fe, 2004, pág. 153.
} 
El aumento de la cuota por motivo de edad constituye un ejercicio abusivo del derecho que tiene la empresa de variar el monto en base a circunstancias objetivas (incorporación de prestaciones o de tecnología más costosa, etc.) al desviarlo para obtener una ventaja económica que no corresponde. Conforme los términos del art. 1071 del Código Civil vigente, se produce un exceso de los límites impuestos por la buena fe. ${ }^{21}$

\subsection{Efectos previstos por el art. 37 de LDC: ¿nulidad o inexistencia?}

El art. 37 de la ley 24.240, dispone que en supuestos de cláusulas abusivas, éstas se "tendrán por no convenidas". Existe discusión doctrinaria sobre la interpretación otorgada a esta previsión legal. Un sector entiende que la disposición recepta la sanción de inexistencia, comprendiendo dentro de él a Alterini, que indica que tal sanción permite superar problemas que acarrean las nulidades, como lo referente a legitimados activos, prescripción de la acción, etc.; o a Sáenz que considera que la inexistencia produce efectos más amplios y protectorios al consumidor. Otro sector, en cambio, interpreta la previsión legal como sanción de nulidad, apoyándose en el párrafo tercero de la norma, que consagra la facultad del consumidor de demandar la nulidad total o parcial del contrato en los casos seguidamente indicados en la misma disposición.

Concordantemente con la postura que considera que la ley recepta la sanción de nulidad, consideramos que la explicación está dada por las diferencias conceptuales entre inexistencia y nulidad. Es decir, acto nulo es aquel que logra constituirse como tal pero que se halla viciado y por ende, al aplicarse tal sanción queda privado de sus efectos propios, tal como sucede con el contrato de medicina prepaga que contiene la cláusula en estudio, en tanto, resulta afectada la causa fin del negocio, entendida ésta como los móviles tenidos en cuenta por el usuario al momento de la contratación, consistente en

\footnotetext{
${ }^{21}$ El nuevo Código Civil y Comercial de la Nación recepta el abuso el derecho como un principio general en el Capítulo 3 sobre Ejercicio de los derechos, art. 10: "Abuso del derecho. El ejercicio regular de un derecho propio o el cumplimiento de una obligación legal no puede constituir como ilícito ningún acto.

La ley no ampara el ejercicio abusivo de los derechos. Se considera tal el que contraría los fines del ordenamiento jurídico o el que excede los límites impuestos por la buena fe, la moral y las buenas costumbres.

El juez debe ordenar lo necesario para evitar los efectos del ejercicio abusivo o de la situación jurídica abusiva y, si correspondiere, procurar la reposición al estado de hecho anterior y fijar una indemnización”.
} 
obtener los servicios ofrecidos a un determinado precio inicial; y afecta el consentimiento del usuario, en virtud de la falta de información sobre el incremento que la empresa efectúa en base a la edad avanzada del mismo. En cambio, en los casos de inexistencia, el acto jurídico no alcanza a nacer como tal, por falta de algún elemento estructurante del mismo, lo que no sucede con el contrato de medicina prepaga que contiene la cláusula en tratamiento, dado que el negocio nace y produce todos sus efectos jurídicos.

En cuanto al alcance de esta sanción de nulidad acogida por la norma en estudio, resulta, que la regla es la nulidad "parcial", siendo la nulidad total, la excepción. El criterio determinante de uno u otro tipo de nulidad está dado por la posibilidad, en el caso concreto, de escisión e independencia de la cláusula viciada del resto del negocio jurídico que permanece válido, produciendo sus efectos propios. La nulidad parcial recae sólo sobre la cláusula reputada abusiva, lo que le permite al usuario, en el contrato en estudio, continuar obteniendo los servicios médicos al precio inicialmente ofrecido. De lo contrario, la nulidad total del contrato no sólo tiene como efecto privar al usuario de la obtención del fin perseguido, sino que también favorece a la empresa predisponente, en tanto si el contrato no puede existir tal cual ella lo diseñó, entonces directamente no es válido en su totalidad.

En síntesis, la aplicación de la nulidad parcial o total depende de la posibilidad de que la cláusula abusiva, en este caso, aquella que habilita a la empresa de medicina prepaga a aumentar la cuota por razón de edad del afiliado, pueda ser apartada del resto del contrato que subsiste. En principio, dicha cláusula puede ser separada y ello no afectar las disposiciones válidas, porque la empresa puede seguir cumpliendo con las prestaciones a su cargo, debiendo afrontar ella la mayor onerosidad que le irroga prestar el servicio a una persona anciana, y el usuario continuar abonando el importe que corresponde sin contar el porcentaje adicional. La empresa puede, para asumir el mayor costo que implica un paciente de edad avanzada, cumplir su obligación con lo que otros afiliados jóvenes y sanos aportan al sistema, o incluso atraer a nuevos adherentes jóvenes.

La regla de la nulidad parcial es la que más se adecua al principio de conservación del acto jurídico, que tanta relevancia adquiere cuando se trata de un contrato de consumo, 
y más aún, un contrato como es el de medicina prepaga donde se encuentra en juego el derecho a la vida y a la salud.

La nulidad en estudio, es además, de carácter "absoluta" atento a que la ley 24.240 es una ley de orden público y los particulares no pueden dejar sin efecto derechos del usuario consagrados por la misma ley y por la Constitución Nacional (art. 42). Se trata del derecho a la salud y el derecho a una información cierta, clara y detallada (art. 4 LDC), que son irrenunciables. Por estos mismos fundamentos, una cláusula abusiva, como la tratada en el presente trabajo, no es susceptible de saneamiento.

\subsection{Facultad del usuario}

El último párrafo del art. 37, reconoce la facultad del consumidor de demandar la nulidad parcial o total del contrato en los supuestos que el mismo párrafo prevé, entre los cuales se encuentra la violación del "deber de buena fe" y el "deber de información". Esta facultad rige en caso de existencia de cláusulas abusivas, como la tratada en el presente trabajo, que no son más, en definitiva, que casos de violación del principio de buena fe contractual en perjuicio del consumidor.

Es el usuario quien determina, en ejercicio de esta prerrogativa, qué alcance otorgar a dicha sanción de acuerdo a sus conveniencias e intereses. Las prestaciones médicas son esenciales para cualquier usuario de determinada edad avanzada, por ende, en principio, la declaración de nulidad que recaiga únicamente sobre la cláusula bajo análisis, es la que permite al usuario no privarse de la finalidad buscada al momento de la contratación.

\subsection{Facultad de integración del juez: Qué debería tener en cuenta para integrar el contrato si declara la nulidad de la cláusula en estudio}

El último párrafo del art. 37, prevé también, la facultad del juez de integrar el contrato cuando declara la nulidad parcial, si ello fuera necesario. Se trata, por ende, de la tarea del magistrado consistente en completar el contenido del contrato ante el vacío que se 
produce por la aplicación de la sanción de nulidad de una o más cláusulas del mismo; o dicho de otro modo, de una tarea de sustitución de la voluntad privada- la del predisponente.

La norma establece que la integración contractual opera "si ello fuera necesario"; por ende, la disposición deja al arbitrio del magistrado la decisión de completar o no el contrato. Para ello, debe tener en cuenta el contexto contractual y determinar si al declarar la nulidad de la cláusula abusiva es necesario sustituirla a efectos de que el usuario pueda continuar obteniendo el servicio requerido, o si por el contrario, ante la ausencia de dicha cláusula igualmente se conserva el fin perseguido por el consumidor. En principio, en un contrato de medicina prepaga, que contiene la cláusula que faculta a la empresa a incrementar la cuota de los afiliados por razón de su edad, entendemos que no sería necesario integrar el contenido contractual, ya que declarada la nulidad parcial, siguen vigentes las demás disposiciones, y por ende, la obligación de la entidad de brindar los servicios médicos prometidos. Dicho de otro modo, es posible la continuación de la finalidad práctica perseguida por el usuario. Pero es necesario atender a las circunstancias particulares de cada caso, lo que puede llevar a que el juzgador decida integrar en el caso concreto.

Consideramos que el juez a la hora de integrar debe tener en cuenta la finalidad subjetiva (causa fin del contrato) buscada por el usuario al momento de la contrataciónen este caso, quedar indemne ante la ocurrencia de una enfermedad- que debe ser preservada a su favor. Al respecto cabe destacar la regulación que ofrece el nuevo Código Civil y Comercial en su art. 989, el cual establece: "Control judicial de las cláusulas abusivas. La aprobación administrativa de las cláusulas generales no obsta a su control judicial. Cuando el juez declara la nulidad parcial del contrato, simultáneamente lo debe integrar, si no puede subsistir sin comprometer su finalidad".

\section{La ley 26.682 de medicina prepaga: consagración expresa de la protección del afiliado de edad avanzada}

En mayo de 2011, el Congreso de la Nación sancionó la ley 26.682 que constituye el Marco Regulatorio de Medicina Prepaga. 
Como expresa Frustagli “(...) se pretende limitar los efectos de ciertas prácticas empresariales que habían dificultado a los afiliados el acceso a prestaciones de salud, como así también controlar desde el Estado a las entidades comercializadoras de planes médicos". 22

La ley recepta la problemática que se presenta en la práctica por la inserción de la cláusula que faculta a la entidad a aumentar el valor de la cuota por razón de edad, y establece protección expresa a favor del usuario.

En primer lugar, el art. 11 toma en cuenta el supuesto que frecuentemente se presenta en la realidad social consistente en el rechazo de afiliación por parte de la prestadora del servicio en virtud de la edad avanzada del sujeto que pretende adherirse al sistema. De este modo, la norma establece que la edad no puede ser tomada como criterio de rechazo de admisión.

A continuación, el art. 12 prevé el supuesto que analizamos, es decir, el de aumento de la cuota en razón de la edad del afiliado. La norma establece lo siguiente: "Personas Mayores de 65 Años. En el caso de las personas mayores de sesenta y cinco (65) años, la Autoridad de Aplicación debe definir los porcentajes de aumento de costos según riesgo para los distintos rangos etarios.

A los usuarios mayores a sesenta y cinco (65) años que tengan una antigüedad mayor a diez (10) años en uno de los sujetos comprendidos en el artículo $1^{o}$ de la presente ley, no se les puede aplicar el aumento en razón de su edad".

Por ende, la norma prevé en primer lugar, que es la autoridad de aplicación de la ley a la que corresponde determinar los porcentajes de aumento de costos considerando el riesgo para cada grupo etario.

En segundo lugar, establece la prohibición expresa dirigida a las empresas de medicina prepaga de aumentar la cuota del afiliado con una antigüedad mayor a diez años con causa en la edad del mismo.

Siguiendo a Frustagli, "se trata de una solución justa pues tales incrementos afectan la reciprocidad sustentada en el largo plazo de la relación contractual. Empero, la prohibición no es absoluta, y fuera del supuesto mencionado, el incremento resulta

\footnotetext{
${ }^{22}$ FRUSTAGLI, Sandra, "La protección del paciente ante las medicinas prepagas", en pàg 3.
} 
viable aunque la fijación de los porcentajes de aumento a partir de los 65 años dependerá de la autoridad de control, no de la empresa". ${ }^{23}$

\section{El criterio sentado por la Jurisprudencia: cláusula abusiva y protección del derecho a la salud}

Los tribunales se han pronunciado a favor de los usuarios de servicios de Medicina Prepaga, considerando que la cláusula en estudio resulta abusiva en los términos del art. 37 de la ley 24.240, y atendiendo al derecho a la salud conforme el art. 42 de la Constitución Nacional y los instrumentos internacionales sobre derechos humanos.

A fin de mostrar el criterio sentado en la jurisprudencia hemos seleccionado fallos de distintos tribunales, los que serán trascriptos en las partes que entendemos que constituyen fundamentos que reflejan el criterio sentado por la jurisprudencia.

En la causa Medicus S.A. c. Secretaría de Comercio e Inversiones ${ }^{24}$, de 1996, la Cámara Nacional de Apelaciones en lo Contencioso administrativo Federal, sala II, confirmó la resolución impugnada de la Dirección Nacional de Comercio Interior en la cual este organismo aplicó una multa a la empresa Medicus S.A que dispuso una cuota adicional mensual de aproximadamente el $47 \%$ del importe que pagaba el afiliado, por haber cumplido 70 años de edad.

Argumentó que "considerando que se trata de un contrato de tracto sucesivo y que los avances de la ciencia y de la tecnología médica podrían determinar la incorporación de nuevos tratamientos exigentes de mayores erogaciones que las previstas por el prestador al comienzo de la relación contractual, el derecho a establecer aranceles adicionales pactado contractualmente (art. 1197 del Código Civil) no aparecería como violatorio del derecho vigente. Pero la eficacia de dicha cláusula depende de su ejercicio no abusivo en relación a las circunstancias del caso", es por ello que determinó que “... el aumento no consensuado de la cuota al cumplir la edad de 70 años, resultó claramente abusivo pues no obstante tratarse de una relación

\footnotetext{
${ }^{23}$ FRUSTAGLI, Sandra, op. cit. , pàg. 16.

${ }^{24}$ CNFed Contencioso Administrativo, Sala II "Medicus S. A. C/ Secretaría de Comercio e Inversiones", 1996/10/08.
} 
contractual concertada 8 años antes, no se había informado al momento de la afiliación que le correspondería un por demás significativo incremento del arancel al cumplir esa edad, siendo que se trataba de una circunstancia claramente previsible a la fecha del comienzo del contrato. Dicho adicional puso al asociado en una situación inequitativa pues la alternativa de rescindir el contrato no le permitía contar con una prestación de servicios de similar calidad ya que si los requería de otra empresa, tendría escasas posibilidades de ser aceptado por su edad ante la probable existencia de restricciones de ingreso similares a las consignadas por Medicus S.A. y, si fuere admitido, estaría sujeto al período de carencia y debería declarar enfermedades contraídas en los últimos años, las que a los efectos de la nueva relación contractual se considerarían preexistentes.

En lo que refiere al deber de información, el tribunal tuvo por acreditado que "el prestador del servicio hizo uso abusivo de la cláusula contractual examinada la que con carácter general le otorga la facultad de establecer aumentos y adicionales no consensuados, por violar el principio de buena fe y de información oportuna al aplicarla esgrimiendo causas claramente previsibles al momento de formalizar el contrato, que no fueron explicitadas, lo que impidió al usuario evaluar oportunamente los costos y la conveniencia de la contratación del servicio. En tales condiciones, este caso encuadra en la previsión del art. 37, último párrafo, según el cual "en caso de que el oferente viole el deber de buena fe, en la etapa previa a la conclusión del contrato o en su celebración o transgreda el deber de información... el consumidor tendrá derecho a demandar la nulidad del contrato o la de una o más cláusulas...”

\section{En la causa Murillo Rafael Norberto c/ SPM Sistema de Protección Médico SA} (Galeno Tim-Life) s/ amparo $^{\mathbf{2 5}}$, de agosto de 2005, la Cámara Nacional en lo Comercial, Sala E, confirmó la resolución del aquo, que admitiendo un recurso de amparo interpuesto por el afiliado, condenó a la entidad a restituirle las sumas que indebidamente le hizo abonar en concepto de aumento de la cuota, y a continuar con las prestaciones médicas prometidas. El tribunal determinó que tales aumentos constituyen

\footnotetext{
${ }^{25}$ CNCom., Sala E, "Murillo, Rafael N. c. SPM Sistema de Protección Médica S.A", 29/08/2005, en LA LEY 2006-B, 365, con nota de Pablo O. Rosales. En igual sentido ya había resuelto la Sala E de la Cam. Nac. de Apel. en lo Com. en la causa Revello Llerena, Ricardo E. c/Qualitas Médica S.A.s/sumarísimo", 8/04/2005, en Microiuris
} 
un desequilibrio de las condiciones contractuales, que podrían poner en peligro el derecho a la salud del actor. Señala que es la accionada la que debe afrontar la mayor onerosidad que se debió tener en cuenta al efectuar los cálculos actuariales tendientes a fijar el precio del servicio.

En el año 2012, en el caso "R. H. O. contra VANSAL SA (UAI SALUD) sobre Amparo"26, la Cámara Nacional de Apelaciones en lo Comercial, Sala F, confirmó la sentencia de primer instancia que había declarado la nulidad de la cláusula que facultaba a la empresa de medicina prepaga a incrementar el valor de la cuota en razón de la mayor edad del afiliado.

La Cámara se pronunció a favor del derecho a la salud del actor, al respecto dijo que: "La CSJN ha reconocido el carácter fundamental del derecho a la salud, íntimamente relacionado con el derecho a la vida - primer derecho del hombre reconocido y garantizado en la Constitución Nacional (dictamen procurador, en fallos:329: 1638)(Fallos: 329:2552 entre muchos otro) (...)

También ha dicho que el derecho a la salud, desde el punto de vista normativo, está reconocido en los tratados internacionales con rango constitucional (art. 75, inc. 22) entre ellos, el art. 12 inc. c del Pacto Internacional de Derechos Económicos, Sociales y Culturales; inc. 1 arts. 4 y 5 de la Convención sobre Derechos Humanos -Pacto de San José de Costa Rica- e inc. 1 del art. 6 del Pacto Internacional de Derechos Civiles

\footnotetext{
${ }^{26}$ CNCom., Sala F, "R. H. O. c/ Vansal S.A. ( UAI SALUD ) s/ amparo", 15-nov-2012, en Microiuris MJ-JU-M-77720-AR | MJJ77720
} 
y Políticos, extensivo no sólo a la salud individual sino también a la salud colectiva (del Dictamen de la Procuración General al que remitió la Corte Suprema en Fallos: $326: 4931)(\ldots)$

De allí que la prestación de los servicios inherentes a la salud no solo la efectúa el Estado sino también que desde la órbita privada se ha dado respuesta contractual a la demanda de los usuarios, a cuyo fin surgieron los sistemas de medicina prepaga (...)

Brindó argumentos conforme las disposiciones de la ley 24.754: "Sin perjuicio de la reciente sanción legal sobre medicina prepaga bajo el número 26.682, al tiempo de la promoción del presente pleito la relación contractual entablada entre los litigantes se hallaba regulada por la ley 24.754; norma que en su artículo primero específicamente prevé que: "Las empresas o entidades que presten servicios de medicina prepaga, deberán cubrir, como mínimo, dentro de sus planes de cobertura médico asistencial, las mismas prestaciones obligatorias dispuestas para las obras sociales, conforme lo establecido por las leyes 23.660, 23.661, 24.455 y sus respectivas reglamentaciones" (...)

La ley 24.754 representa el equilibrio entre la medicina prepaga y la economía toda vez que pondera delicados intereses en juego -la integridad psicofísica, salud y vida de las personas-, y más allá de su constitución como empresas, los entes de medicina prepaga tienen a su cargo una trascendental función social muy por encima de toda cuestión comercial (CSJN, "Cambiaso Perés de Nealon Celia M. A. y otros c/ Centro de Educación Médica e Investigaciones Médicas" del 28/8/2007).

Esta interpretación, por lo demás, se ajusta a lo propuesto por el propio magistrado a quo, quién en sus considerandos sostuvo, en punto a la imposibilidad de aumentar la cuota en función de la edad, que: "cabe aclarar que ello no implicará que la demandada mantenga la cuota del afiliado en el importe percibido al mes de agosto de 2007, sino que el mismo se corresponderá con aquel que a valores actuales y en equivalencia al que se cobra a los restantes afiliados a los que no se les aplicó el incremento en virtud de la edad, resulta pertinente para el plan de salud que el actor tiene contratado con la demandada" (v. fs. 288/289, punto 2) (...) En el sub lite parece que la directiva del juzgador se orientó más bien a disponer que no se soslaye lo previsto en la Resolución 9/2004 de la Ex Secretaría de Comercio 
Interior -modificada por la Resolución 175/07- en cuanto dispone los términos en los cuales habrán de consolidarse los incrementos en el precio del contrato de medicina prepaga.

Ante tal panorama, parece prudente concluir que la cuota mensual del actor deberá ajustarse a la que se cobra a los demás afiliados -menores de 70 años- que contrataron igual plan médico.De modo que la mensualidad podrá sufrir variaciones, siempre y cuando aquéllas no contravengan otras disposiciones que regulan la materia y sean adecuadamente implementadas conforme las resoluciones citadas y normativa concordante”.

En la causa B. A. E. c/ Omint S.A. de Servicios s/ ordinario ${ }^{27}$, del 2013, la Cámara Nacional de Apelaciones en lo Comercial, Sala C, confirmó el fallo de primer instancia que condenó a Omint S.A. de Servicios a que se abstuviera de continuar aplicando sobre la cuota que pagaba el actor el aumento que le había venido cobrando a partir de que aquél había cumplido de 70 años de edad. Asimismo, condenó a la empresa a reintegrar al demandante las sumas que por tal concepto éste había desembolsado.

La Cámara resolvió a favor del derecho a la salud del afiliado expresando que: "Un aumento de esa naturaleza -esto es, sólo fundado en la mayor edad del afiliados- podría condenar al involucrado a quedar desprotegido en su salud, dado que, como es obvio, podría él ser colocado -por razón de la mayor onerosidad del contrato- en situación de no poder continuar la relación, con la consecuente desprotección que ello supone cuando transita los tiempos de su vida en los que, cabe presumir, mayor protección necesita.

Sobre la cláusula impugnada dijo que: "Una cláusula semejante debe, por ende, tenerse por no escrita en los términos del art.37 de la ley 24.240, toda vez que, al afectar de ese modo el derecho a la salud del consumidor involucrado, aparece desnaturalizando el contrato al permitir que, si este último no pudiera absorber el incremento que se le aplica, su contraparte adquiera, correlativamente, el derecho a liberarse de la obligación de asistirlo, precisamente cuando, como dije, cabe presumir que aquél

\footnotetext{
${ }^{27}$ CNCom., Sala c, "B. A. E. c/ Omint S.A. de Servicios s/ ordinario", 9-may-2013, en Microiuris MJ-JUM-80442-AR | MJJ80442 | MJJ80442
} 
habrá de necesitar más que nunca de los servicios convenidos.

La cuestión pone en juego los derechos que a los consumidores reconoce el art. 42 de la Constitución Nacional(...)

La contundencia de los textos constitucionales citados es tal que, según mi ver, la ley 24.240 no puede considerarse una ley más: es reglamentación específica de esas normas constitucionales, por lo que, por imposición de la escala normativa establecida en el art. 31 de la Constitución Nacional, ella debe prevalecer por sobre cualquier otra norma que se le oponga.

$Y$, por tratarse de una ley de orden público (art. 65), forzoso es concluir que la solución que aquí se propicia no puede verse obstada por la circunstancia de que el actor no haya cuestionado en forma inmediata el incremento que le fue aplicado.

$Y$ esto, pues, ese aumento debe considerarse alcanzado por lo dispuesto en el citado art.37 de la LDC en cuanto manda tener por no escritas ".b) Las cláusulas que importen renuncia o restricción de los derechos del consumidor o amplien los derechos de la otra parte.".

Se refirió a las obligaciones que pesaban sobre la entidad prestadora del servicio, expresanque que: "Para esos supuestos, era obligación de la demandada, en su calidad de sociedad comercial titular de una empresa con objeto especializado y prestadora de un servicio fuertemente imbuido de interés general, instrumentar algún mecanismo que, similar al reseñado, evitara su necesidad de aplicar esos aumentos para cubrir su eventual mayor costo.

$Y$ digo que la adopción de tal temperamento no era discrecional para ella sino obligatoria, por dos razones principales.

La primera viene dada por el hecho de que, en tanto administradora del sistema, su parte se hallaba obligada a extremar su diligencia en la prestación de una cobertura integral a sus afiliados, obligación que no podría entenderse debidamente cumplida si se admitiera su posibilidad de colocar a éstos frente al riesgo de quedar sin esa cobertura en la etapa más desvalida de sus vidas.

Y la segunda de las razones anticipadas deriva del hecho de que una interpretación 
contraria colocaría a la demandada en una situación lindante con la asunción de obligaciones meramente potestativas: si se le reconociera la facultad de aumentar el importe de las cuotas que deben abonar sus afiliados a partir de cierta edad, ella podría por esta vía desprenderse de aquellos adherentes cuya permanencia en el sistema le resultara más gravosa.

Me refiero al hecho de que, como es sabido, a partir de cierta edad, el afiliado que pierde la cobertura que tiene, suele ser rechazado como tal por otras prestadoras de esta especie, de lo que se deriva que, no sólo nos encontramos aquí con un contrato de adhesión cuyas cláusulas deben ser apreciadas con precaución -en los términos de la conocida doctrina elaborada al respecto-, sino que, además, es necesario tener presente que el afiliado en esas condiciones podría enfrentarse a la imposibilidad de rescindir su relación con la demandada a efectos de contratar otra prestadora, lo cual lo colocaría en virtual estado de indefensión frente al aumento de dicha cuota (...) El aumento, por ende, no fue lícito, debiendo la modificación respectiva tenerse por no escrita. Los pagos realizados, por ende, fueron sin causa, por lo que deben ser devueltos al afiliado (...)

En julio de 2014, en el caso "Anchezar Carlos Juan c/ Omint SA de Servicios s/ ordinario" ${ }^{28}$, la Cámara Nacional de Apelaciones en lo Comercial, Sala C, confirmó la sentencia de primer grado que había admitido el reclamo del afiliado.

La cláusula sobre la cual debió resolver el tribunal establecía lo siguiente: "De acuerdo con el plan asistencial elegido, la cuota mensual sufrirá incrementos a partir de la fecha en que el beneficiario titular y/o los beneficiarios dependientes cumplan (.) 60, 65, 66 ó 70 años de edad. Estos aumentos que obedecen al incremento en los gastos y en la tasa de utilización de los servicios médicos, podrán alcanzar hasta un $50 \%$ ó $60 \%$ según categoría etárea."

Conforme dicha cláusula, a partir de julio 2004 la entidad demandada incrementó la

\footnotetext{
${ }^{28}$ CNCom., Sala c, “Anchezar Carlos Juan c/ Omint SA de Servicios s/ ordinario”, 16-jul-2014en Microiuris, MJ-JU-M-88285-AR | MJJ88285
} 
cuota del actor en un $26,4 \%$, por haber alcanzado 70 años de edad. Se acredito que el vínculo contractual comenzó a partir del $1^{\circ}$ de abril de 1994. La Cámara se pronunció a favor del derecho a la salud del afiliado expresando que "tanto en la Constitución de 1853 (art. 33, derechos no enumerados), su modificación por la Convención Constituyente de 1957 (art. 14 bis), cuanto en la que actualmente rige (arts. 14 y 42), el derecho a la salud tiene un reconocimiento expreso y así ha sido declarado por la Corte Suprema Nacional.

De otro lado, el Pacto Internacional de Derechos Económicos, Sociales y Culturales, art. 12, reconoce que toda persona tiene derecho al disfrute del más alto nivel posible de salud física y mental (ap. $\left.1^{\circ}\right)$ (...)Y también la Declaración Universal de los Derechos Humanos (art.25.1.) y la Declaración Americana de los Derechos y Deberes del Hombre (art. XI) reconocen el derecho a la salud.

Se pronunció sobre la finalidad del contrato de medicina prepaga: "La medicina prepaga implica asegurar cobertura al asociado frente a la enfermedad, que prevé que será otro quien afrontará los gastos y honorarios que en general suelen ser altos; y de su lado, por parte de la empresa, que sabe que no todos los asociados han de utilizar el servicio en la medida de las cuotas que sufragan. En otros términos, en la base del contrato está la seguridad de contar con asistencia médica y servicios médicos en los casos de enfermedad, de manera que una parte -la empresa-se obliga a brindar esa prestación, y la otra -el asociado- contrata en función de esa obligación y abona la cuota. Esta es, en esencia y sintéticamente, la ecuación sobre la cual el contrato es redactado -predispuesto- y a tales términos se sujeta el adherente (esta Sala, "Garat, Eduardo Rodolfo c/ Omint S.A. de servicios", 19.3.10; id., "Havandjián, Jorge c/ Consolidar Salud S.A.", 2.10.12; íd., "Iaconniani, Adriana Elsa c/ HSBC Salud S.A.", 13.5.14).

La Cámara fundamentó también su resolución conforme las disposiciones de la ley de medicina prepaga: "En el curso del año 2011 se sancionó la ley 26.682 como marco regulatorio de las empresas de medicina prepaga, siendo ésta una ley de orden público (art. 28).

El objeto de ese cuerpo normativo es "establecer el régimen de regulación de las empresas de medicina prepaga, los planes de adhesión voluntaria y los planes 
superadores o complementarios por mayores servicios que comercialicen los Agentes del Seguro de Salud (ASS) contemplados en las Leyes Nros. 23.660 y 23.661" (art. 1).

(...) Claro está, entonces, que en la actualidad es la Autoridad de Aplicación quien determina los porcentajes de aumento de las cuotas, que es autorizado previo cumplimiento por parte de las empresas de medicina prepaga, del procedimiento establecido en el decreto reglamentario 1993/11: 5, inc. g): "Las entidades que pretendan aumentar el monto de las cuotas que abonan los usuarios deberán presentar el requerimiento a la Superintendencia de Servicios de Salud (...)

Sobre la cláusula cuestionada el tribunal expresó que: "Se trata, en definitiva, de una cláusula indirecta de extinción, pues importa tanto como forzar al asociado -cuya situación vital lo pone en una condición de particular vulnerabilidad-, a pagar el aumento impuesto por la empresa o aceptar la extinción del vínculo -frustrando, de este modo, la cobertura esperada por el consumidor justamente para la vejez-; evidentemente, una cláusula semejante contraría la finalidad del contrato, que tiene elementos de previsión, de asegurarse contra las contingencias propias de la decadencia humana. Una disposición semejante debe, por ende, tenerse por no escrita en los términos del art.37 de la ley 24.240, toda vez que, al afectar de ese modo el derecho a la salud del consumidor involucrado, aparece desnaturalizando el contrato al permitir que, si este último no pudiera absorber el incremento que se le aplica, su contraparte adquiera, correlativamente, el derecho a liberarse de la obligación de asistirlo, precisamente cuando cabe presumir que aquél habrá de necesitar más que nunca de los servicios convenidos (esta Sala, "Hajvandián, Jorge c/ Consolidar Salud S.A.", 2.10.12; íd., "Balaguer, Alberto Eduardo c/ Omint S.A. de Servicios s/ ordinario", del 9.5.13)”.

\section{Reflexiones finales}

La cláusula que faculta a la empresa de medicina prepaga a incrementar el monto de la cuota del afiliado en razón de su edad, resulta abusiva según los términos del art. 37 inc. b de la ley 24.240, en tanto implica una renuncia de los derechos del consumidor o una ampliación de los derechos de la otra parte, que no es más que un caso de desnaturalización de obligaciones del inc.a, que la norma prevé como estándar general. 
En otras palabras, el traslado del riesgo al usuario en base a su edad, carece de justificación y desnaturaliza la obligación principal de la empresa (prestación del servicio médico).

Se trata de la renuncia de derechos fundamentales como es el derecho a la salud, consagrado en el art. 42 de la Constitución Nacional y en numerosos instrumentos internacionales sobre Derechos Humanos, y el derecho a la igualdad, en tanto se pretende un trato diferente hacia las personas mayores de edad en base a un criterio- la edad- que no resulta un medio razonable para aumentar el monto de la cuota (finalidad). Asimismo, una renuncia a la protección de los intereses económicos del mismo art. 42 de la Constitución Nacional, al generar para el usuario de la tercera edad un costo mayor para enfrentar enfermedades que se suelen presentar en edades avanzadas.

La entidad está habilitada para aumentar el valor de la cuota en base a parámetros objetivos, pero extender esta facultad a los casos en que el afiliado, en razón de su edad, requiere más menudo de sus servicios, importa una ampliación de sus derechos en los términos del inc. b del art. 37 LDC.

Dicha cláusula genera una doble vulnerabilidad: la derivada de la condición de usuario que siempre es la parte más débil de los contratos por adhesión, y aquella que sufren las personas mayores de edad en la sociedad actual. Se produce una enorme inseguridad atento a que el asociado se encuentra tranquilo de contar con cobertura médica y abona por ello un precio inicial que ha aceptado, hasta el momento en que alcanza determinada edad y la empresa decide unilateralmente incrementar dicho precio en base a ella, produciéndose de esta manera la modificación de un elemento esencial del contrato, como lo es el precio.

Ante la existencia de una cláusula como la estudiada, el fin primordial debe ser preservar la relación jurídica, esto es, la continuidad de las prestaciones médicas; de lo contrario, el usuario quedaría indefenso y vería frustrado su propósito de quedar indemne frente a una eventual enfermedad. La sanción legal que más se adecua a esto es la nulidad parcial ya que permite la conservación del acto jurídico.

Entendemos que el juez que debe resolver un caso como éste debe considerar especialmente: a) las normas constitucionales e internacionales que protegen el derecho a la salud y el derecho a la información y los intereses económicos del consumidor (normas internacionales sobre derechos humanos, art. $42 \mathrm{CN}$ y ), la protección que 
emana de toda la ley 24.240 en su conjunto, cuyo espíritu es la defensa del consumidor frente al poder que ostenta el proveedor, la protección que emana de la ley 26.682 regulatoria de las empresas de medicina prepaga, que como vimos prohíbe expresamente la inserción de la cláusula en cuestión; b) la finalidad subjetiva (causa fin del contrato) buscada por el usuario al momento de la contratación- en este caso, quedar indemne ante la ocurrencia de una enfermedad- que debe ser preservada a su favor. c) los principios generales del Derecho que se encuentran en juego, tales como la buena fe contractual (art. 1198 código Civil vigente- art. $9^{\circ}$ del Código Civil y Comercial de la Nación), el principio del abuso del derecho (art. 1071 Código Civil vigente-art. $9^{\circ}$ del Código Civil y Comercial de la Nación)

El criterio sentado por la jurisprudencia argentina, en concordancia con la declaración como cláusula abusiva en los términos del art. 37 de la LDC ha sido fundamental para la protección del derecho a la salud del usuario de medicina prepaga frente al poder de estas empresas. Las sentencias judiciales reflejan el fenómeno de la constitucionalizaciòn del Derecho Privado, pues los jueces han considerado el Derecho en su totalidad $\mathrm{y}$ han resuelto como vimos conforme las normas y principios constitucionales. Dicho fenómeno ha reforzado la protección del usuario de medicina prepaga, pues hoy ya no enfocamos solamente nuestra mirada en la ley de Defensa del Consumidor, sino también en la Constitución Nacional y los instrumentos internacional sobre derechos humanos con jerarquía constitucional.

Florencia Vazzano

Institución: Facultad de Derecho de la Universidad Nacional del Centro de la Provincia de Buenos Aires

Correo electrónico: florencia.vazzano@azul.der.unicen.edu.ar 


\section{Referencias bibliográficas}

ARIAS CÁU, Esteban J., "La defensa del consumidor: pasado, presente y futuro a la luz del Proyecto de Còdigo Civil 2012", disponible en http://www.acaderc.org.ar/doctrina/la-defensa-del-consumidor-pasado-presente-yfuturo-a-la-luz-del-proyecto-de-codigo-civil-de-2012.

BERBERE DELGADO, Jorge C., "El usuario de Empresas de Medicina Prepaga. Su naturaleza jurídica”, en La Ley, Suplem. Règimen jurídico de la Medicina Prepaga, mayo 2011, p. 22.

FARINA, Juan M., "Defensa del Consumidor y del Usuario. Comentario exegético de la ley 24.240 y del Dec. Reglamentario 1798/94”, Astrea, Buenos Aires, 1995.

FRUSTAGLI, Sandra, "La protección del afiliado en la empresa de Medicina Prepaga", Trabajos del Centro... en ; "El contrato como marco de tensión entre utilidad y derechos de la personalidad', en RCyS, julio 2010.

LORENZETTI, Ricardo L., "Consumidores", Rubinzal Culzoni, Santa Fe, 2003; Tratado de los contratos, Rubinzal-Culzoni, Santa Fe, 2004.

MAC DONALD, Andrea F., "La medicina prepaga y el aumento de las cuotas a los consumidores", en Revista Microiuris, MJ-DOC-5087-AR | MJD5087, 2010.

MORELLO, María Silvia-SCHERMAN, IDA A., "Los contratos de Medicina Prepaga y el derecho a la salud de los niños y adolescentes bajo la mirada de los instrumentos de derechos humanos", en Revista Derecho de familia: Revista Interdisciplinaria de Doctrina y Jurisprudencia, Buenos Aires, 2009.

SAENZ Luis R. J., "De los términos abusivos y las cláusulas ineficaces”, en Picasso y Vazquez Ferreyra (direct.), Ley de Defensa del consumidor, Comentada y Anotada, La Ley, Avellaneda, Pcia. de Bs. As., 2009. 
STIGLITZ, Gabriel, “Cláusulas abusivas. Inconstitucionalidad de normas restrictivas contra los consumidores", disponible en

http://www.academiadederecho.org/upload/biblio/contenidos/Jurisprudencia_Rosarina_

Clausulas_AbusivasStiglitz.pdf.

WEINGARTEN, Celia, "Cláusulas abusivas. Análisis económico y jurisprudencial", Revista Microuris, MJ-DOC-5409-AR | MJD5409, 2011. 